\title{
Detecting Crowded Trades in Currency Funds
}

\author{
Momtchil Pojarliev $\quad$ Richard M. Levich
}

1st Draft: 12 May 2009

Revised: 22 December 2009

Comments welcomed

PRELIMINARY

(Please do not quote without the authors' permission)

The financial crisis of 2008 highlights the importance of detecting crowded trades due to the risks they pose to the stability of the financial system and to the global economy. However, there is a perception that crowded trades are difficult to identify. To date, no single measure to capture the crowdedness of a trade or a trading style has developed. We propose a methodology to measure crowded trades and apply it to professional currency managers. Our results suggest that carry became a crowded trading strategy towards the end of Q1 2008, shortly before a massive liquidation of carry trades. The timing suggests a possible adverse relationship between our measure of style crowdedness and the future performance of the trading style. Crowdedness in the trend following and value strategies confirm this hypothesis.

We apply our approach to currencies but the methodology is general and could be used to measure the popularity or crowdedness of any trade with an identifiable time series return. Our methodology may offer useful insights regarding the popularity of certain trades - in currencies, gold, or other assets - among hedge funds. Further research in this area might be very relevant for investors, managers and regulators.

Key words: Foreign Exchange, Hedge Funds, Style Investing, Crowded Trades JEL Classification: F31

\section{Contact details:}

Momtchil Pojarliev, Hathersage Capital Management LLC, 77 Bleecker St., Ste. 531, New York, NY 10012, USA; Tel: 212-260-4606; Email: momtchil@hathersage.com .

Richard M. Levich, New York University Stern School of Business, Finance Department, 44 West $4^{\text {th }}$ Street, New York, NY 10012-1126, USA; Tel: 212-998-0422, Fax: 212-9954256; Email: rlevich@stern.nyu.edu . 


\section{Detecting Crowded Trades in Currency Funds}

\section{Introduction}

Over the last twenty years, institutional investors have greatly increased their allocations to alternative investments like hedge funds, and away from traditional assets like equities and bonds. For example, a survey conducted by the National Association of College and University Business Officers (2008) found that US university endowments larger than \$1 billion allocated more than $20 \%$ of their assets to hedge funds. This strategy was partly the result of a conventional belief that hedge funds could pursue more diverse strategies, that diversification is the key for successful investing and that the returns on alternative assets will have little or no correlation with returns on traditional investments.

However, the transfer of substantial assets under management to hedge fund harbored considerable risks for investors and the broader financial system. Addressing the Economic Club of New York in 2004, Timothy Geithner, then President of the Federal Reserve Bank of New York, put the matter quite bluntly. "While there may well be more diversity in the types of strategies hedge funds follow, there is also considerable clustering, which raises the prospect of larger moves in some markets if conditions lead to a general withdrawal from these 'crowded' trades."1

\footnotetext{
${ }^{1}$ Remarks by President Timothy F. Geithner before the Economic Club of New York, May 27, 2004.
} 
In many ways, Geithner's conjecture about returns in crowed trades was realized during the global financial crisis. In 2008 many investors discovered that they were less diversified than planned. The HFRI Fund Weighted Composite Index (an equallyweighted composite of over 2,000 hedge funds) declined 19.04\% in 2008 offering little joy to battered equity investors. The negative returns of many market neutral funds in a period of declining equity markets suggests that what investors had perceived to be uncorrelated alpha turned out to be equity beta. Allocations to commodities (another asset class presumed to provide diversification) were costly too, with crude oil crashing from a $\$ 146.50$ high in July 2008 to a $\$ 42.79$ low in December 2008 . The experience of 2008 confirmed what had been previously documented in academic research a decade earlier (see Chow, et al. 1999), i.e. in turbulent markets, asset returns generally become more volatile and more highly correlated. Thus, diversification tends to fail exactly when it is most needed, i.e. in falling markets.

What forces underlie this increase in correlation? Deleveraging and forced selling are plausible causes. In turbulent times, volatility swells and investment managers are forced to reduce the size of their exposures to avoid breaching tracking-error limits. At the same time, investors become more risk averse and withdraw money from risky assets. Outflows trigger additional selling. Prime brokers raise margin requirements for hedge funds, which compounds the problem as managers have to cut positions further. ${ }^{2}$ As a

\footnotetext{
${ }^{2}$ Assuming a margin requirement of $15 \%$, an investor with $\$ 15$ equity could support a position of up to $\$ 100$ (or $15 / 15 \%$ ). An increase of the margin requirement to $25 \%$ would mean that he could support a position of only $\$ 60$ (or $15 / 25 \%$ ), i.e. he would be forced to reduce his positions by $40 \%$.
} 
result, returns in many asset classes drop concurrently, and the returns on many strategies move as if they reflected the same trade. ${ }^{3}$

Exhibit 1 (Panel A) shows the correlations between the weekly returns on the S\&P 500 index, crude oil and spot AUD/JPY (a proxy for the carry trade) in the second half of 2008. The results show that these presumably "independent assets" exhibited very high correlation, with correlation between the S\&P 500 index and AUD/JPY strikingly high at $84 \%$. The correlation between S\&P 500 index and crude oil was $56 \%$ in this period, which is remarkably higher than the long term correlation of $2 \%$ (see Panel B).

In turbulent periods, positioning and being aware of crowded trades becomes crucial as traders may try to exit trades at the same time and in the same direction. The phenomenon of large numbers of traders exiting similar trades at the same time creates liquidity problems as everyone is rushing to exit a "burning house." However, in order to leave a "burning house," it is not enough to reach the exit, but rather to persuade someone from the outside to take your place, i.e. to take the other side of the trade. Therefore, it is hardly a surprise that "positioning" and the concentration, or popularity, or the crowded nature of certain trades and trading styles are highly discussed topics among investment managers. ${ }^{4}$ Changes in investor positioning are used often to justify

\footnotetext{
${ }^{3}$ Pedersen (2009) compares the risk of being in a crowded trade when a shock occurs to being in a crowded theater assuming someone shouts "fire." The real risk of being injured by the fire is exacerbated by the endogenous risk of being trampled by other theater patrons. Pedersen develops a stylized model in which "liquidity spirals" amplify and spread the initial shock, so that selling begets more selling, tighter risk management, withdrawals of capital, and so on.

${ }^{4}$ At the Quant Invest 2009 conference in Paris, Robert Litterman of Goldman Sachs is reported to have said that computer-driven hedge funds needed to identify new areas to exploit, as some areas had become
} 
price moves which can not be explained by fundamentals. "The market sold off because of profit taking" is an often used argument to justify price moves despite the lack of fundamental news. ${ }^{5}$ Recent academic studies (Evans and Lyons, 2002) also find a strong correlation between order flow in the foreign exchange market and subsequent currency rate changes. Because currencies have proved to move without strong connection to fundamentals, positioning is often at the center of debate among currency professionals. ${ }^{6}$

To illustrate the importance of positioning, as a part of their periodic foreign exchange research commentaries some banks have introduced Commodities Futures Trading Commission data on market positioning in currency futures. ${ }^{7}$ These analyses focus on the positioning of the non-commercial or speculative accounts. Custodians also are able to take advantage of their proprietary equity flow data in order to gauge positioning. For example, State Street Bank and Trust (SSBT) is said to make use of their proprietary flow data to gauge positioning across different currencies. ${ }^{8}$ To date, however, no single measure to capture the crowdedness of a trade or trading style has developed.

In this paper, we develop a new approach to detect positioning and identifying crowded trades. We apply our approach to currencies but the methodology is general and could be used to measure the popularity or crowdedness of any trade with an identifiable time

so overcrowded that they are no longer profitable. "Quant Hedgies Must Fish In Fresh Waters Goldman," Reuters, December 1, 2009.

${ }^{5}$ Profit taking implies in this case that the market was long.

${ }^{6}$ There is a widespread consensus in academic literature that macroeconomic variables offer little help in exchange rate forecasting. In a seminal paper, Meese and Rogoff (1983) show that random walk forecasts outperform economic models of exchange rates. This is called the foreign exchange disconnect puzzle. Rogoff and Stavrakeva (2008) discuss the recent evidence.

${ }^{7}$ See Deutsche Bank, Global Markets Research "DB FX Positioning Indices”, May 18, 2009. 
series return. Currencies may become more highly correlated when investors pursue similar trading strategies. For example, there is little fundamental reason to expect high correlation between currency returns on the GBP/CHF cross and the NZD/JPY cross. However, a carry trader, who establishes a long position in high yielding currencies by taking a short position in a low yielding currencies, could very likely have been long the two crosses (long GBP vs. CHF and long NZD vs. JPY) over much of the last twenty years, as interest rates in New Zealand and the United Kingdom were generally higher than interest rates in Japan and Switzerland, respectively. ${ }^{9}$ Increasing popularity of the carry trade could help account for the greater correlation of these two crosses in recent years (see Exhibit 2). Indeed, the rolling annual correlation of the GBP/CHF and NZD/JPY cross rates rose above 0.50 in the late 1990 s, and then fell sharply after the liquidation of the Yen carry trade between June 1998 and December 1999. ${ }^{10}$ The correlation rose again in 2007 and peaked in the fourth quarter of 2008, a period which once again experienced massive liquidation of carry trades.

Analyzed in this way, currency traders appear more focused on exposure to a particular risk factor or trading strategy and less so on exposure to particular currencies. A large short JPY exposure might be offset by long CHF exposure as both currencies rallied during the recent carry trade liquidation. And a seemingly small short JPY exposure becomes more risky when combined with exposures to other carry trade proxies.

\footnotetext{
${ }^{8}$ See Froot and Ramadorai $(2005,2008)$ for analyses that rely on the SSBT equity flow data.

${ }^{9}$ See Froot and Thaler (1990) for a survey of the carry trade.

${ }^{10}$ The USD/JPY spot rate fell from levels above 145 to almost 100 during this time period.
} 
Previous research (see Pojarliev and Levich (PL), 2008a) has shown that four factors (or styles), which represents the return on several well-known currency trading strategies and the foreign exchange volatility explain a significant part of the variability of the returns of professional currency managers. Thus, exposures to these factors might be a useful way to gauge the popularity or crowdedness of a trading strategy. We define style crowdedness as the percentage of the funds with significant positive exposure to a given style less the percentage of the funds with significant negative exposure to the same style (contrarians). ${ }^{11}$ To estimate crowdedness, we rely on data for 80 currency managers for three years between April 2005 and March 2008. We estimate style betas using the four factor model proposed in PL (2008a). We use higher frequency, weekly return data to obtain efficient parameters estimates for rolling 26-week periods.

Our initial results are quite promising and consistent with a view that crowded trades harbour potential risk once a change in fundamentals or sentiment induces liquidation of positions. Our analysis shows that carry became a crowded strategy towards the end of our sample period (March 2008), i.e. just a few months before the crash in October/November 2008. Trend and value trading strategies exhibit similar patterns. Investors "gave up" on trend at the end of our sample period and the trend strategy experienced big gains a few months later. Value became a popular contrarian strategy (a high proportion of the funds exhibited significant negative value exposure) just a few

\footnotetext{
${ }^{11}$ Alternatively, each manager could be weighted by their assets under management (AUM). In a related paper, Jylhä and Suominen (2009) find that AUM at hedge funds are significantly related to contemporaneous and expedited future returns from a risk-adjusted carry trade. Unfortunately, we do not have data on AUM for the managers in our sample to experiment with this alternative measure.
} 
months before performing exceptionally well. Our results suggest that style crowdedness may impact the future performance of its respective style.

In the next section of the paper, we lay out our methodology for estimating crowdedness. In section 3, we report our estimates of crowdedness, present some empirical evidence on its determinants and discuss the relationship of current crowdedness to future performance. Conclusions and implications of our findings are in the final section. 


\section{Data Description and Definition of Crowdedness}

To measure exposure to styles, we follow the approach used in PL (2008a) and use a standard factor model of the form:

$$
R_{t}=\alpha+\sum_{i} \beta_{i} F_{i, t}+\varepsilon_{t}
$$

where

$R$ is the excess return generated by the currency manager, defined as the total return $\left(R_{t}^{*}\right)$ less the periodic risk-free rate $\left(R_{F, t}\right)$

$\alpha$ is a measure of active manager skill,

$F$ is a beta factor, that requires a systematic risk premium in the market,

$\beta$ is a coefficient or factor loading that measures the sensitivity of the manager's returns to the factor, and

$\varepsilon$ is a random error term.

To implement this approach, we require data on currency manager returns and factors that proxy for types of trading strategies and exposures that currency managers would be likely to utilize.

We make use of the same data base as used in Pojarliev and Levich (2008b), i.e. daily return data for currency managers listed on the Deutsche Bank FXSelect trading platform. ${ }^{12}$ We obtain daily data for 80 funds between April 2005 and March 2008. Only

\footnotetext{
${ }^{12}$ Launched in March 2005, FXSelect is an open platform, which allows clients of Deutsche Bank to allocate their funds to different currency managers. Any currency manager can apply for registration in the platform and be accepted if he satisfies the following criteria: a) Managers must be able to provide a daily track record for at least the last 18 months verified by a third party, b) They cannot have had more than a $20 \%$ performance drawdown over the last 12 months, c) Assets under management must be at least 15 million USD, and d) Satisfactory criminal and regulatory searches on key individuals. We are grateful to Neville Bulgin and Rashid Hoosenally from Deutsche Bank for supplying the data. More information
} 
15 of these funds have a complete 3-year track record. To correct for accounting errors and eliminate data outliers, we transform the daily returns into weekly returns by using Wednesday observations. ${ }^{13}$ The data base is especially useful as it provides us with high frequency returns and allows for the correction of backfill and survivorship bias. ${ }^{14}$

\section{$\underline{\text { Data for Risk Factors }}$}

As risk factors we make use of the same proxies as in PL (2008b).

\section{Carry Factor}

We use the Deutsche Bank G10 Harvest Index as the proxy for the returns of a carry strategy. This index reflects the return of being long the 3 high-yielding currencies against being short the 3 low-yielding currencies within the G10 currency universe. The index is rebalanced quarterly. Every quarter the currencies are re-ranked according to their current 3-month Libor rate. The Bloomberg code for this factor is DBHVG10U Index.

\section{Trend Factor}

As a proxy for the trend-following factor, we use the AFX Currency Management Index. ${ }^{15}$ The AFX Index is based on trading in seven currency pairs weighted by their

about FXSelect can be find in the brochure "FXSelect: An Asset Allocation Solution," Deutsche Bank, Global Markets Foreign Exchange, 2006.

${ }^{13}$ We decided to use Wednesday as fewer bank holidays fall on Wednesday. Managers were based in different locations (US, UK, Australia, Switzerland, Monaco, Spain, Sweden, Germany, Ireland and Canada).

${ }^{14}$ For more information see Pojarliev and Levich (2008b).

${ }^{15}$ Monthly data for this index are available at the AFX web site (http://www.ljmu.ac.uk/LBS/95327.htm). We are grateful to Jason Laws from the Liverpool John Moore University for providing daily data. We transformed the daily returns into weekly returns by using the Wednesday observations. 
volume of turnover in the spot market, with returns for each pair based on an equallyweighted portfolio of three moving average rules (32, 61 and 117 days). ${ }^{16}$

\section{$\underline{\text { Value Factor }}$}

We use the Deutsche Bank FX PPP Index as the proxy for the returns of a value strategy. To gauge relative value, Deutsche Bank prepares a ranking based on the average daily spot rate over the last three months divided by the PPP exchange rate as published annually by the OECD. The FX PPP index reflects the return of being long the 3 currencies with the highest rank (undervalued currencies) against being short the 3 currencies with the lowest rank (overvalued currencies) within G10 currency universe. The Bloomberg code for this factor is DBPPPUSF Index.

\section{Currency Volatility Factor}

We use the Deutsche Bank Currency Volatility Index as the proxy for foreign exchange volatility. This index is calculated as the weighted average of 3-month implied volatility for nine major currency pairs (as provided by the British Bankers Association) with weights based on trading volume in the BIS surveys. ${ }^{17}$ The Bloomberg code for this factor is CVIX Index. We use the first difference for this factor in equation (1) as it is not a trading strategy. In the case of the previous three factors, we use returns.

\footnotetext{
${ }^{16}$ The seven currency pairs are EUR-USD, USD-JPY, USD-CHF, GBP-USD, EUR-JPY, EUR-GBP, and EUR-CHF.

${ }^{17}$ The nine currency pairs are EUR-USD, USD-JPY, USD-CHF, USD-CAD, AUD-USD, GBP-USD, EUR-JPY, EUR-GBP, and EUR-CHF.
} 


\section{Definition of Crowdedness}

We define the crowdedness of style $F$ at time $t\left(C_{F, t}\right)$ as the percentage of the funds with significant positive exposure to style $F$ less the percentage of the funds with significant negative exposure to the same style (contrarians).

$$
C_{F, t}=a_{F, t}-b_{F, t}
$$

where

$a_{F, t}$ is the percentage of funds with significant positive exposure to risk factor $F$ over the period $t-25$ through $t$, i.e. we use rolling windows of 26 weeks to estimate the exposures to the risk factors with equation (1).

$b_{F, t}$ is the percentage of funds with significant negative exposure to risk factor $F$ over the period $t-25$ through $t$-25, i.e. we use rolling windows of 26 weeks to estimate the exposures to the risk factors with equation (1).

For both positive and negative exposures, we use a standard 95\% confidence level and t-value with absolute value greater than or equal to 2.0 to indentify significant exposure. 


\section{Empirical Results}

\section{a. Time Variation in Crowdedness}

To determine which funds have significant exposure to each trading strategy, we estimate equation (1) using a rolling sample of 26 weekly observations over the 3 -year (156 week) sample period, April 6, 2005 - March 26, 2008. Thus, we are able to estimate crowdedness on 131 dates commencing September 28, 2005 running through March 26, 2008. Funds on the platform for less than 26 weeks are excluded from our analysis. The number of funds used to estimate crowdedness varies from week to week as new funds join the platform and some funds exit the platform. Exhibit 3 plots the number of funds used to estimate crowdedness. The number of funds is the lowest (22) at the beginning of the sample. It then rises steadily toward 60 in late 2006 as the number of funds joining the platform exceeds the number of funds leaving the platform and remains stable around 55 for the remainder of the sample.

To illustrate the methodology, Exhibit 4 plots the estimated t-statistics for alpha and the betas for fund \#6 (indicating fund \#6 in the data base). This fund has a full track record of 3 years (156 weeks), so we obtain t-statistics for 131 weeks, using a rolling window of 26 weeks. Exhibit 4 shows that over the entire sample period, fund $\# 6$ never achieved a significant alpha. Fund \#6 generally had positive exposure to carry and trend and negative exposure to value and volatility. However, these exposures were not consistently significant throughout the entire sample period, i.e. the t-statistics of the 
factor loadings were not constantly above 2 (or below -2 ) ${ }^{18}$ For example, the exposure to value was most of the time not significant, but there were periods (at the beginning of 2006 and towards the middle of 2007) when this manager exhibited strong contrarian value positioning, i.e. the t-statistics of the value factor were between -2 and -3 . Thus, manager \#6 appears to have discretionary trading authority, tracking Value at some times and not at others, and taking other positions not significantly related to the Carry and Trend factors.

\section{Crowdedness}

Using t-values from equation (1), we estimate crowdedness using equation (2) for three of the four factors, i.e. carry, value and trend. As the fourth risk factor does not represent return on a trading strategy, but simply the first difference of the implied foreign exchange volatility, we do not estimate crowdedness for volatility.

\section{Carry Crowdedness}

Exhibit 5 plots our measure for carry crowdedness between September 28, 2005 and March 26, 2008. We also plot $a_{\text {carry,t }}$ and $b_{\text {carry,t }}$ representing the percentage of the funds with significant positive exposure to carry and the percentage of the funds with significant negative exposure to carry (the contrarians). We also graph the performance of the carry strategy until the end of 2008.

\footnotetext{
${ }^{18} \mathrm{We}$ are referring here to the results of the rolling regressions. PL $2008 \mathrm{~b}$ show that manager \#6 exhibits significant positive exposure to carry and trend and no significant exposure to value and volatility over the entire 3 year time period.
} 
Exhibit 5 suggests an interesting story. At the beginning of our sample, carry crowdedness was minimal (around 5\%) as only about $10 \%$ of the funds in our analysis were significantly exposed to carry and the "contrarians" were about $5 \%$. As carry started to exhibit very strong performance between the middle of 2006 and the middle of 2007 , the number of both carry managers and contrarians increased. The first group was chasing the good performance of the carry strategy; the second group was betting that carry is overdone. As the first group was only slightly larger than the second, carrycrowdedness increased steadily to about $15 \%$. In the summer 2007 , the contrarians started to "die-out" as the performance of the carry strategy accelerated. ${ }^{19}$ As a result carry crowdedness reached a peak at 31\% at the end of March 2008 as the contrarians either gave up or were forced out of the market. Interestingly, the carry strategy exhibits a substantial decline just a few months later. While the popular press attributes the liquidation of the carry trade to the credit crunch and the decline of the equity markets, a possible reason behind the rapid liquidation of carry trades might be that this strategy had become crowded. This result is consistent with the "liquidity spiral" story suggested by Pedersen (2009) and the shrinking hedge fund asset base discussed in Jylhä and Suominen (2009).

\section{Trend Crowdedness}

Exhibit 6 plots our measure for trend-crowdedness. In contrast to the carry-crowdedness, trend was a relative crowded strategy at the beginning of our sample period. The

\footnotetext{
${ }^{19}$ PL (2008b) found out that managers who did not survive had as a group a significantly negative exposure to carry between April 2005 and March 2008. Ironically, although the liquidation of the carry
} 
percentage of the funds which had significant positive trend exposure was between $25 \%$ and $35 \%$, with only a very small percentage of the funds being "contrarians". As most of the currency research in the 1990s (see for example Levich and Thomas, 1993) advocated trend-following strategies, this is not a surprise. However, as trend failed to deliver returns, crowdedness declined to only $4 \%$ at the end of our sample. This change did not result from a rise in the numbers of contrarians, but rather that trend-followers appeared to be "giving up." Ironically, the trend strategy did deliver excellent performance about six months later in the fall 2008.

\section{$\underline{\text { Value Crowdedness }}$}

Exhibit 7 plots our measure for value-crowdedness. The pattern is different, but the main story is similar. The percentage of the funds which exhibited positive significant exposure to value was relatively small and constant around $10 \%$. On the other hand, the percentage of the contrarians (funds with significant negative value exposure) was rising steadily during the investigated time horizon, and peaked at $32 \%$ towards the end of the period. Thus the contrarian value trade became progressively more crowded reaching about $25 \%$ near the end of our sample. A few months later in the summer 2008, the financial crisis intensified and undervalued currencies rose, causing substantial losses to contrarian value traders, who had crowded into this position.

trade might have hurt carry managers, the strong performance of the carry strategy until the credit crunch was devastating for managers betting on liquidation of carry trades. 


\section{b. Determinants of Crowdedness}

As we can see from Exhibits 5, 6 and 7, our measure of crowdedness can vary considerably. For example, Carry Crowdedness rose from a low of -7\% as of December 28, 2005 to a high of $31 \%$ as of March 26, 2008. Trend crowdedness ranged between 4\% and $34 \%$. And Value crowdedness varied between about $+12 \%$ early in the sample to about $-27 \%$ toward the end.

In this section we consider the question of what drives crowdedness. There are two channels through which a strategy becomes popular or crowded - (1) Through existing managers moving into or out of a strategy, and (2) as managers leave or join the DB platform which determines the size of our data sample. Exhibit 8 summarizes the composition of our universe of managers at the low and at the high in crowdedness for each style.

Carry Crowdedness was at its low on December 28, 2005. At that point, 41 funds were active on the platform (13 of these funds (31\%) did not survive until the end of our time horizon). Of the 41 funds, 2 had significant carry exposure, 5 were betting against carry and 34 had no significant carry exposure. Carry Crowdedness peaked at the end of our sample period, i.e. on March 26, 2008. At that point, 54 funds were active on the platform (with a track record of at least 26 weeks). From these 54 funds, 28 were active as of December 28, 2005 and 26 were new funds. 
Of the new funds, 11 (or $42 \%$ ) had significant carry exposure. Furthermore, a significant proportion from the existing funds with no carry exposure (10 funds or $24 \%$ ) converted to having positive carry exposure. Thus, only one of the carry managers at the peak of Carry Crowdedness was a carry manager when Carry Crowdedness was at its low. The increase in the Carry Crowdedness seems to have been driven by 1) many new funds with positive carry exposure joining the platform, and 2) a large number of the existing funds with no carry exposure, adopting a carry style.

Trend Crowdedness was at its peak on December 6, 2006. At that point, 59 funds were active on the platform (18 of these funds (30\%) did not survive until the end of our time horizon). Of these 59 funds, 21 had significant trend exposure, 1 was betting against trend and 37 had no significant trend exposure. Trend Crowdedness was at its low at the end of our time horizon, i.e. on March 26, 2008. At that point, 54 funds were active on the platform (with a track record of at least 26 weeks). Of these 54 funds, 41 were active as of December 28, 2005 and 13 were new funds. Of the new funds, 11 (or 84\%) had no significant trend exposure. Furthermore, of the 21 funds with positive trend exposure, 14 funds (or 66\%) exited the trend style, i.e. had no exposure to trend as of the end of the time horizon. From the 22 managers with trend following exposure at the time of the peak in Trend Crowdedness, only 2 managers exhibited trend exposure at the time of the low in the Trend Crowdedness. Thus, the decline in the Trend Crowdedness seems to be driven by 1) new funds joining the platform with no trend exposure, and 2) a large number of the initial trend-followers "giving up" on trend. 
Value Crowdedness was at its peak on January 18, 2006. At that point, 41 funds were active on the platform and 12 of these funds (or 29\%) did not survive until the end of our time horizon. Of these 41 funds, 6 had significant value exposure, 1 was betting against value and 34 had no significant value exposure. From the 6 funds with positive value exposure, 4 funds left the value style and 2 funds exited the platform. None of the value funds as of January 18, 2006 remained positively exposed to value as of March 12, 2008. Value Crowdedness was at its low towards the end of our time horizon, i.e. on March 12, 2008. At that point, 56 funds were active on the platform (with a track record of at least 26 weeks). From these 56 funds, 29 were active as of December 28, 2005 and 27 were new funds. Of the new funds, eight (29\%) had significant negative value exposure (contrarian). The decline in value crowdedness seems to be driven by a) new funds joining the platform betting against value, and $b$ ) a large number of the existing funds (10 funds) converting to a value contrarian strategy.

As we can see from Exhibit 8, the change in crowdedness across the different styles is driven by the change in styles of the existing managers, but also in the different styles characteristics of the new joiner. What may be behind these shifts? It is reasonable to assume that there should be a link between speculative positions in some strategy and the expected returns on that strategy. If expected returns go up, then optimal portfolio allocation tilts toward higher weights on that strategy and we expect to find that more fund managers have significant betas versus that strategy. Expected returns on a strategy could be modelled as a function of past returns on that strategy. In other words, we expect to see herding in the sense that positive returns on a strategy attracts newcomers, 
and negative returns on a strategy encourage managers to abandon a strategy. As we measure crowdedness over 26 weeks, we cumulate the performance of the different strategies also over 26 weeks. Our methodology (of confirming whether or not a manager is following some strategy) relies on estimating betas, and needs a number of weeks before we can determine whether or not a manager has shifted his allocations in response to higher expected returns in any strategy. So there is a lag of 26 weeks between when returns on a strategy first appear and when we (the researcher) can identify a statistically significant relationship, or style beta. Therefore, we have to lag the cumulative past performance of the strategies by 26 weeks to explore the linkage with our measure of crowdedness.

Exhibit 9 summarizes the correlations between our measure of crowdedness and the lagged performance of the trading strategies. Panel A contains results over the whole sample period. Panels B and C show results for the first and second halves of the sample. Panel A suggests some herding of the carry strategy: good past performance attracts newcomers. The opposite appears to be true for Value Crowdedness: strong past performance does not attract more managers. This is understandable. In the case of the value strategy, returns are generated from long (short) positions in under- (over-) valued currencies that become more fairly valued. Strong past performance in value presages lower expected future return from this strategy. In the case of the trend style, the correlation between past performance and crowdedness is remarkably close to zero. A possible reason for that might be that trend performed close to flat during these time 
periods. As performance was neither encouraging nor discouraging it played little role in attracting new managers.

It is interesting that the correlation of the carry style with crowdedness is slightly negative in the second sub-sample (see Panel C). Carry performed especially badly towards the end of this time period and managers might have expected a rebound.

The link between expected return of a strategy and the popularity (crowdedness) of this strategy is weaker than we have expected. Several factors may account for this. First, not all managers have discretionary authority to allocate toward a given currency strategy, even when it appears to be profitable. For example, a fund that specializes in trend following, and has stated so in an investment mandate, cannot shift and take positions in carry trades even when they appear likely to generate profits. Only discretionary managers can shift their trading style in response to a new market environment. So only a small number of managers in the sample have the ability to shift. We should not expect that $100 \%$ of all the managers in any sample will follow carry (for example) when carry is profitable, because some of those managers are trend followers or value managers, by design or choice. Second, managers might be constrained in joining the platform; a fund needs 18 months of track record to list on DB FX Select. Therefore, even if a new carry manager might be keen to join the platform (as he expects future carry returns to be high), he would have to wait for the appropriate track record before to join. Finally, the 
past return of a strategy might not be the best proxy of what managers think regarding future return of a strategy. ${ }^{20}$

\section{c. Current Crowdedness and Future Performance}

Our measures of crowdedness offer an interesting interpretation of events in currency markets over the financial crisis period. In the last quarter of 2008, the less popular and less crowded strategy worked best for carry and value plays. The data show that a higher than usual percentage of the funds were significantly exposed to carry, and these funds suffered during the market turbulence in the last quarter of 2008 when carry collapsed. Similarly, a high percentage of the funds were significantly betting against value, but value delivered strong performance, causing substantial losses for the contrarians who were caught wrong-footed.

The story for trend is different: Trend was a crowded strategy at the beginning of our sample period, but this crowdedness led simply to flat performance for the trend strategy during this period. After managers gave up on the trend strategy, trend delivered strong a performance, leading to opportunity costs, but no actual losses. These differences among strategies might also be related to the fact that returns to carry and value trading exhibit negative skewness, while trend exhibits positive skewness. ${ }^{21}$ Crowdedness in carry and

\footnotetext{
${ }^{20}$ We tried relating crowdedness in a strategy to expected returns in that strategy which for carry were modelled as the interest differential plus the expected exchange rate change. Expected returns for PPP and Trend Following were simply the expected exchange rate change, which for PPP were based on some rate of convergence to parity. We found only weak evidence that crowdedness responded to expected returns modelled in this way.

${ }^{21}$ See PL (2008a) for descriptive statistics of the currency risk factors.
} 
value leaves investors in those strategies vulnerable to sudden stops in capital flows that support the carry trade, or to shifts in fundamentals that shift sentiment toward undervalued currencies. Thus, crowdedness in carry and value might signal future sharp moves. ${ }^{22}$ By comparison, a crowded trend style simply implies low future returns. This is as expected, as trend-followers are unlikely to experience a sudden drawdown as price changes will trigger a change in positioning. For example, trend-followers who are long the EURUSD cross, will exit this position (and even go short) when the EUR declines against the USD below a certain level. In contrast, carry and value strategies would not lead to changes in positioning when the price moves against the positions.

Our results suggest a possible relationship between the performance of a trading strategy (or style) and our measure of crowdedness. While our sample period is too short for more formal statistical tests, our analysis suggests that there may be an adverse relationship between crowdedness and style performance, in particular in the carry and value styles. This will hopefully stimulate some future research on this subject.

\footnotetext{
${ }^{22}$ See Brunnermeier, Nagel and Pedersen (2008) for an analysis linking carry trading with crash risk.
} 


\section{Conclusions}

The financial crisis of 2008 highlights the importance of detecting crowded trades due to the risks they pose to the stability of the financial system and to the global economy. However, there is a perception that crowded trades are difficult to identify. ${ }^{23}$ To date, no single measure to capture the crowdedness of a trade or a trading style has developed.

Using a unique data base of professional foreign exchange manager returns, we propose and estimate a new measure for style crowdedness. Our measure of crowdedness suggests that carry became a crowded strategy in the first quarter of 2008 at the end of our sample period. The liquidation of the carry trade in the second half of 2008 implies some adverse relationship between crowdedness and the future performance of the carry trade strategy. Value exhibits an analogous pattern with managers crowding the contrarian value trade. The percentage of value-contrarian managers peaked towards the end of our sample period, and the value strategy exhibited especially strong performance a few months later. In the case of trend, managers suffered mostly opportunity losses. Managers appeared to "give up" on trend in early 2008 only to experience a revival of the performance of trend-following strategies.

\footnotetext{
${ }^{23}$ For example, in attempting to measure the extent of carry trade activity, Galati, Heath and McGuire (2007) analyze various banking and capital flow data. The authors do not offer numerical estimates. They conclude that "growth in carry trades funded in yen and Swiss francs has probably contributed to increased activity in these currencies" but that "the available data do not allow for a more refined measurement of the size of carry trade positions." And on the same theme, in their analysis of carry trading and currency movements in 2008, McCauley and McGuire (2009) conclude that "Carry trades always defy measurement." It is worth stressing that our approach does not provide a quantitative estimate of the volume of carry trades outstanding.
} 
Our results suggest that our measure of crowdedness deserves closer monitoring. In our short sample period, the anecdotal evidence shows that crowdedness may provide useful signals regarding the future performance of a given strategy. As more and more funds attempt to exploit market timing strategies by switching among trading styles in order to deliver alpha and not simply beta, crowdedness may again become a significant element of market dynamics. Indeed as US dollar interest rates remained close to zero during 2009, commentators allege that a surging US dollar based carry trade has developed that will have dire consequences once it begins to unwind. ${ }^{24}$ Additional data will allow researchers to track when our measure of crowdedness reveals any unwinding and whether changes in crowdedness correlate with exchange rate movements ${ }^{25}$.

Hearings held by the U.S. House Financial Services Committee in 2009 considered proposals for a "systematic risk regulator" who could take into account, among other things, that crowded trades elevate the risk to the financial system because crowding is itself a source of instability. But as some observers have noted, "the sad truth [is] that crowded trades are difficult for the government to identify." ${ }^{, 26}$ Our methodology may offer useful insights regarding the popularity of certain trades - in currencies, gold, or other assets - among hedge funds. Although, we apply our approach to currencies, it could be easily extended to other asset classes. Further research in this area could be relevant for both investors and managers. For example, it would be interesting to

\footnotetext{
${ }^{24}$ Nouriel Roubini, "Mother of all carry trades faces an inevitable bust," Financial Times, November 1 2009.

${ }^{25}$ Currency managers' returns are usually available on a daily basis to plan sponsors. Thus, some institutional investors could update and follow our measure of crowdedness on a daily basis.

${ }^{26}$ Sebastian Mallaby, "A Risky 'Systemic' Watchdog," Washington Post, March 2, 2009.
} 
investigate if the hedge fund community become too long "equity risk" ahead of the collapse in equity indices in the second half of 2008. 


\section{References}

Deutsche Bank. “DB FX Positioning Indices,” May 18, 2009.

Chow, G., Jacquier, E., Kritzman, M., and K. Lowry. 1999. “Optimal Portfolios in Good Times and Bad.” Financial Analysts Journal, (May/June): pp. 65-73.

Brunnermeier, Markus K., Stefan Nagel and Lasse H. Pedersen. (2008) “Carry Trades and Currency Crashes,” NBER Working Paper No. 14473, November.

Evans, Martin D. D. and Richard K. Lyons. (2002) "Order Flow and Exchange Rate Dynamics,” Journal of Political Economy, Vol. 110, no. 1 (Feb): 170-80.

Froot, K. A., and T. Ramadorai. "Currency Returns, Intrinsic Value, and Institutional Investor Flows." Journal of Finance 60, no. 3 (June 2005): 1535-1566.

Froot, K. A., and T. Ramadorai. "Institutional Portfolio Flows and International Investments." Review of Financial Studies 21, no. 2 (April 2008): 937-971.

Froot, K. and R. Thaler. 1990. "Anomalies: Foreign Exchange," Journal of Economic Perspectives, vol. 4, no. 3 (Summer): 179-92.

Galati, Gabriele, Alexandra Heath and Patrick McGuire. 2007. "Evidence of Carry Trade Activity," BIS Quarterly Review, (September): 27-41.

Jylhä, Petri and M. Suominen. (2009) "Speculative Capital and Currency Carry Trade Returns," working paper, Helsinki School of Economics.

National Association of College and University Business Officers (2008), 2007 NACUBO Endowment Study, Washington, D.C.

McCauley, Robert and Patrick McGuire. 2009. "Dollar Appreciation in 2008: Safe Haven, Carry Trades, Dollar Shortage and Overhedging," BIS Quarterly Review, (December): 85-93.

Meese, Richard A., and Kenneth Rogoff, 1983, "Empirical Exchange Rate Models of the Seventies: Do They Fit Out of Sample?" Journal of International Economics, vol. 14, February, pp. 3-24.

Levich, R.M., and L.R. Thomas, III. 1993. "The Significance of Technical Trading-Rule Profits in the Foreign Exchange Market: A Bootstrap Approach." Journal of International Money and Finance, vol. 12, no. 5 (October):451-474.

Pedersen, Lasse Heje. (2009) "When Everyone Runs for the Exit," NBER working paper, No. 15297, August 2009. 
Pojarliev, M. and R.M. Levich. 2008a. "Do Professional Currency Managers Beat the Benchmark?" Financial Analysts Journal, (Sep/Oct): vol. 64, no. 5.

Pojarliev, M. and R.M. Levich. 2008b. "Trades of the Living Dead: Style Differences, Style Persistence and Performance of Currency Fund Managers?" NBER working paper 14355, September 2008.

Rogoff, K. and V. Stavrakeva (2008), "The Continuing Puzzle of Short Horizon Exchange Rate Forecasting", NBER Working paper 14071. 
Exhibit 1: Correlation of Returns on Equity, Crude Oil, and a Currency CrossRate

Panel A: Between July 2008 and December 2008

Weekly Data, 07/04/2008 - 12/26/2008, 26 weekly observations

\begin{tabular}{|l|c|c|c|}
\hline & S\&P 500 & Crude Oil & AUD/JPY \\
\hline S\&P 500 & 1 & 0.558 & 0.841 \\
\hline Crude Oil & 0.558 & 1 & 0.555 \\
\hline AUD/JPY & 0.841 & 0.555 & 1 \\
\hline
\end{tabular}

Panel B: Between January 1990 and December 2008

Weekly Data, 01/12/1990 - 12/26/2008, 990 weekly observations

\begin{tabular}{|l|c|c|c|}
\hline & S\&P 500 & Crude Oil & AUD/JPY \\
\hline S\&P 500 & 1 & 0.019 & 0.323 \\
\hline Crude Oil & 0.019 & 1 & 0.132 \\
\hline AUD/JPY & 0.323 & 0.132 & 1 \\
\hline
\end{tabular}

Data source: Bloomberg and authors' calculations.

Note: Correlations computed using log differences in the spot prices. 


\section{Exhibit 2: Rolling Yearly Correlation of Returns on Two Cross Rates}

Weekly Data, 01/04/1991 - 03/27/2009

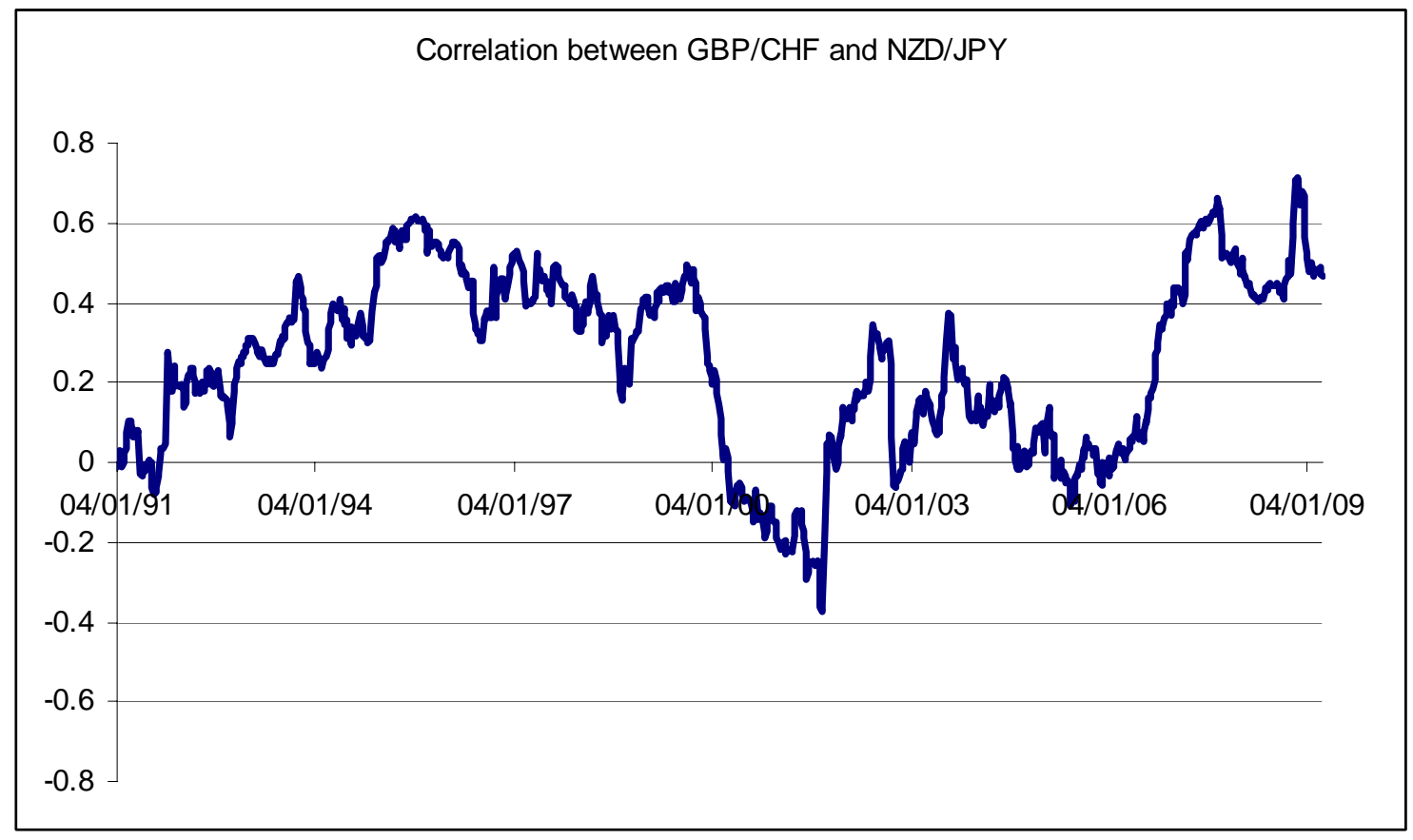

Data source: Bloomberg and authors' calculations.

Note: Correlation is computed by using a rolling sample of 52 weekly observations. The first correlation measure is for January 4, 1991. Currency returns are computed from January 12, 1990 until March 27, 2009. 
Exhibit 3: Number of funds used to estimate crowdedness

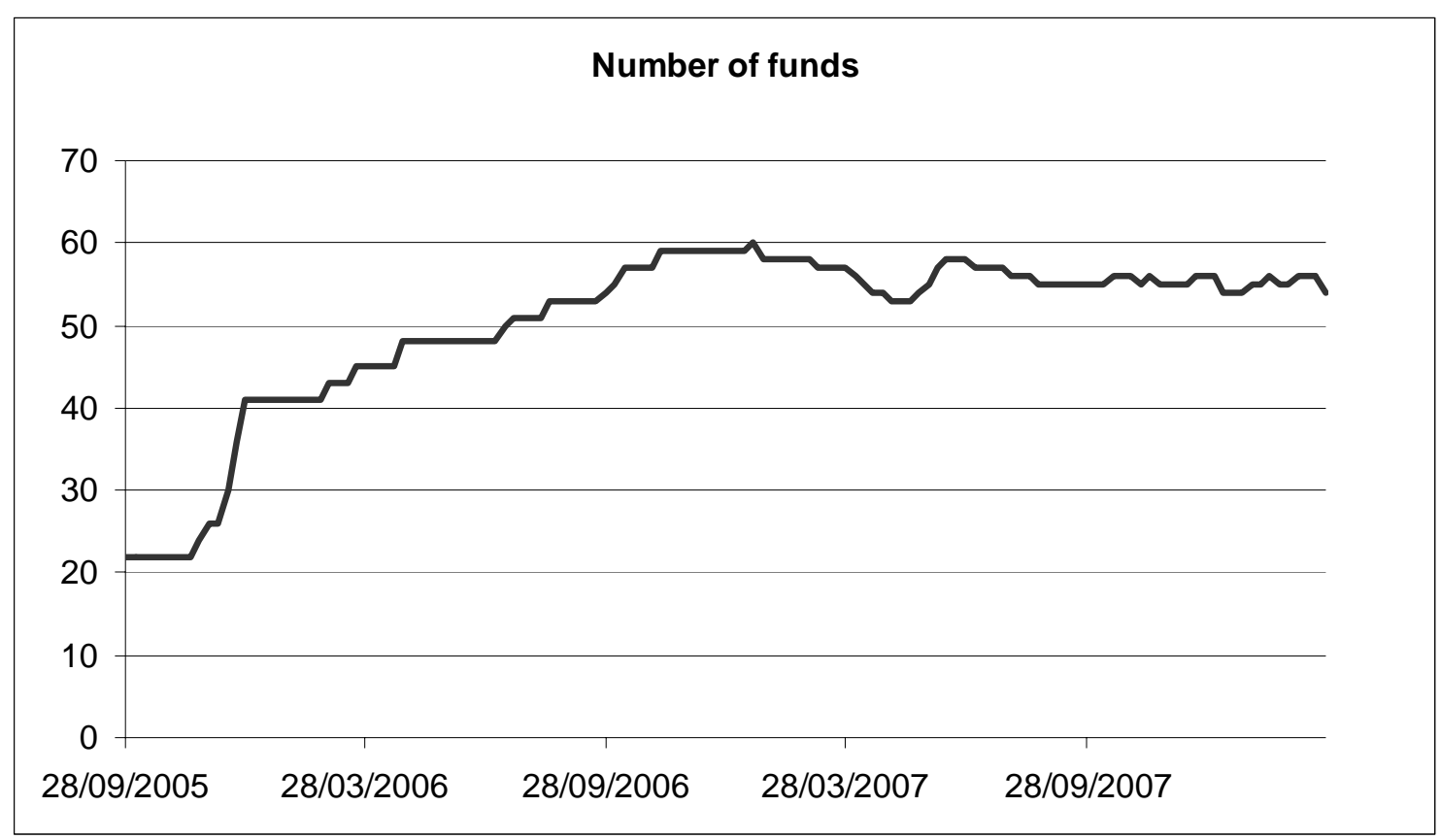

Source: Deutsche Bank and authors' calculations

Number of funds on the platform in week $t$, which have been active since week $t-25$, where $t=9 / 28 / 2005-3 / 26-2009$ or 131 weeks. Funds with a track record of less than 26 weeks ( $1 / 2$ year) are not used for estimating of crowdedness. 


\section{Exhibit 4: Estimated t-values for alpha and beta coefficients for manager \#6}

Rolling regression results for $R_{t}=\alpha+\sum_{i} \beta_{i,} F_{i, t}+\varepsilon_{t}$ where $R$ are the returns of manager $\# 6 ; \mathrm{i}$ = Carry, Trend, Value and Volatility; $\mathrm{t}=1, \ldots 26$ weekly observations.

The first regression is estimated with 26 weekly observations from 4/06/2005 until $9 / 28 / 2005$. The last regression is estimated with 26 weekly observations from $10 / 03 / 2007$ until 3/26/2008. The sample contains 131 rolling windows.

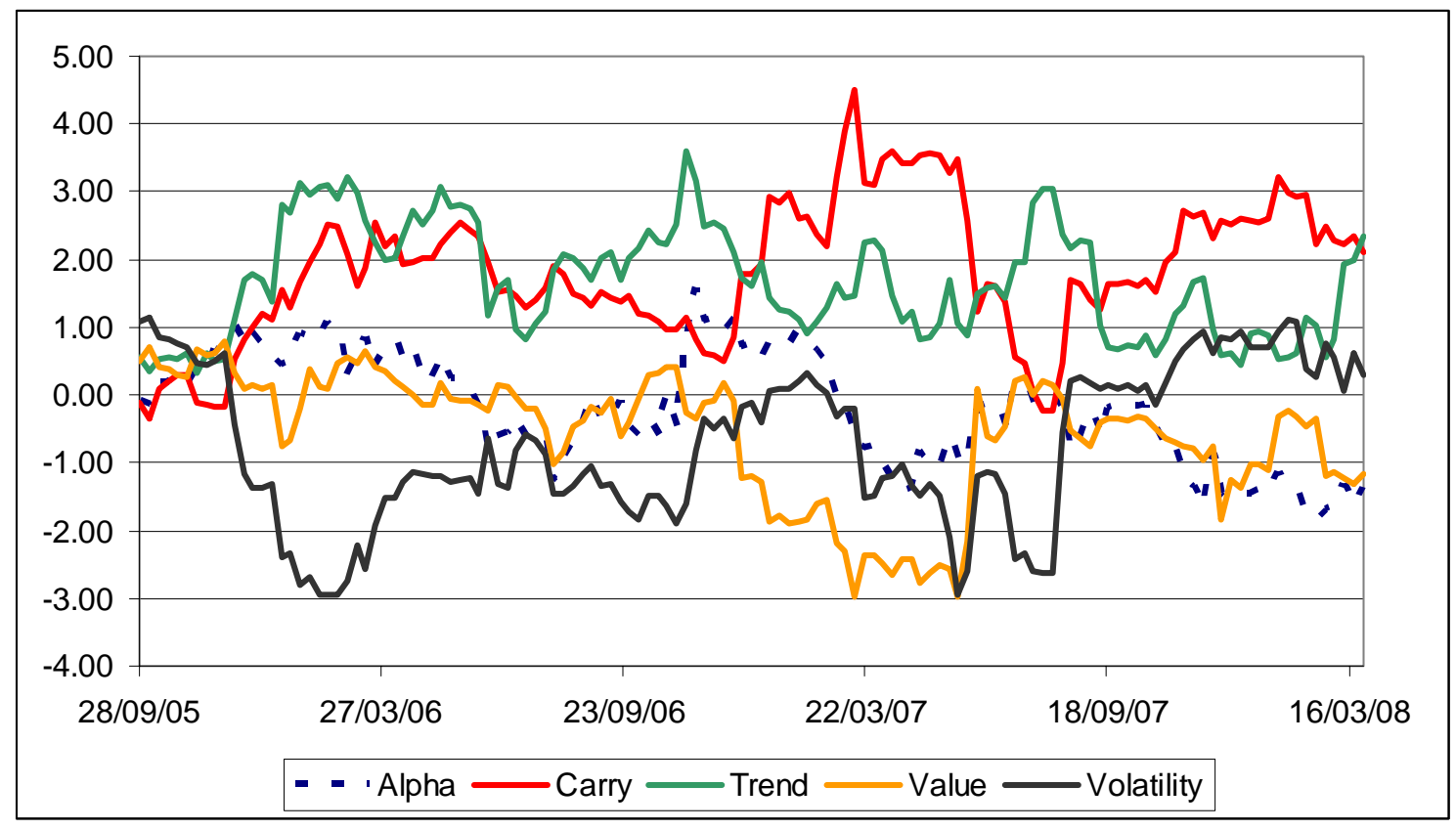




\section{Exhibit 5: Carry Crowdedness}

Rolling regression results for $R_{j, t}=\alpha_{j}+\sum_{i} \beta_{i, j} F_{i, t}+\varepsilon_{j, t}$ for manager $j$ active on the platform at least from week $t-25$ onwards. The number of managers varies according to Exhibit 3.

Carry crowdedness is defined as in Equation \#2. The first measure for crowdedness is estimated as of 9/28/2005 with 26 weekly observations from 4/06/2005 until 9/28/2005. The last measure of crowdedness is estimated as of 3/26/2008 with 26 weekly observations from 10/03/2007 until 3/26/2008. The sample contains 131 rolling windows.

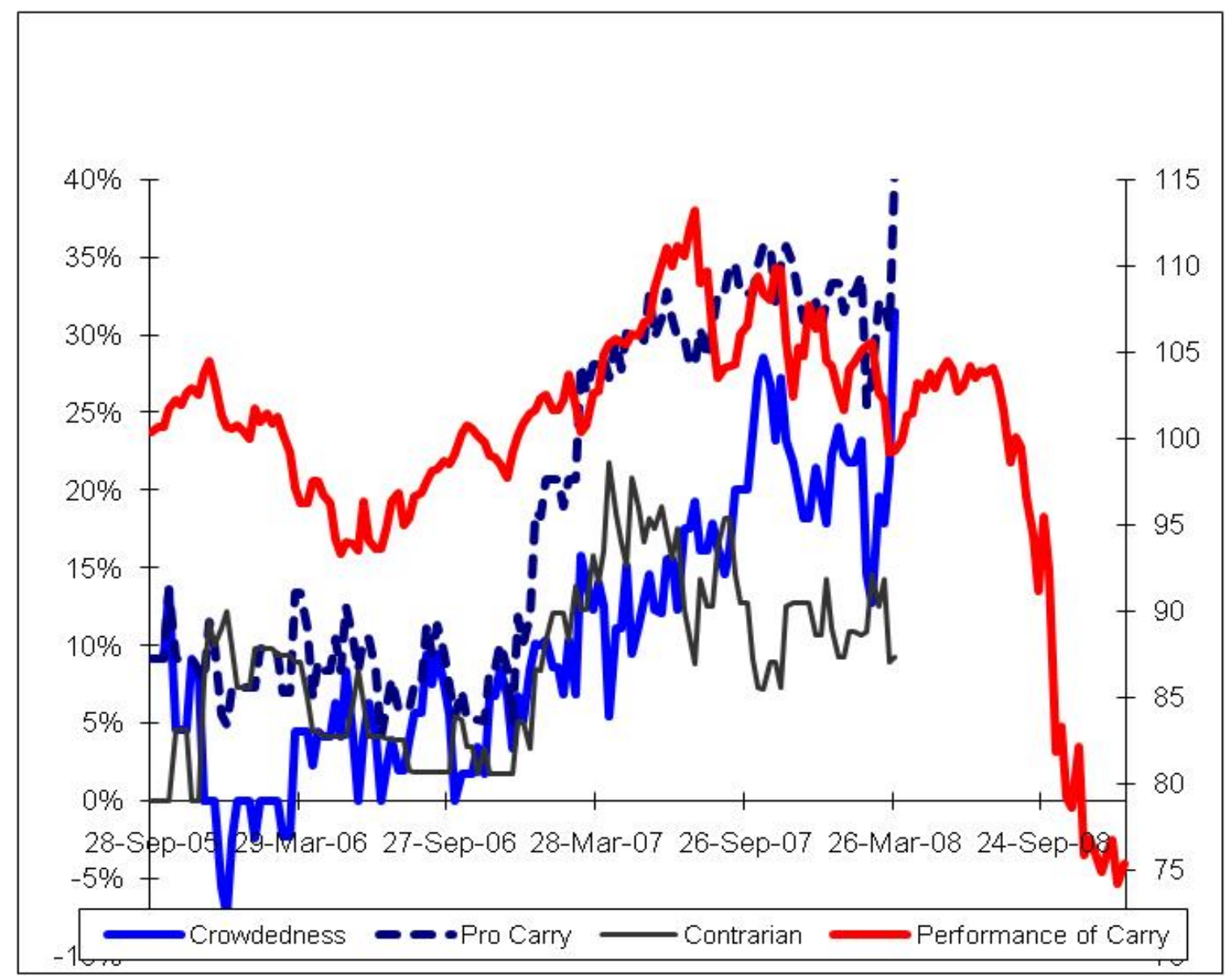

Crowdedness measures are on left-hand scale and Performance measure is on the righthand scale. 


\section{Exhibit 6: Trend Crowdedness}

Rolling regression results for $R_{j, t}=\alpha_{j}+\sum_{i} \beta_{i, j} F_{i, t}+\varepsilon_{j, t}$ for manager $j$ active on the platform at least from week $t-25$ onwards. The number of managers varies according to Exhibit 3.

Trend crowdedness is defined as in Equation \#2. The first measure for crowdedness is estimated as of 9/28/2005 with 26 weekly observations from 4/06/2005 until 9/28/2005. The last measure of crowdedness is estimated as of 3/26/2008 with 26 weekly observations from 10/03/2007 until 3/26/2008. The sample contains 131 rolling windows.

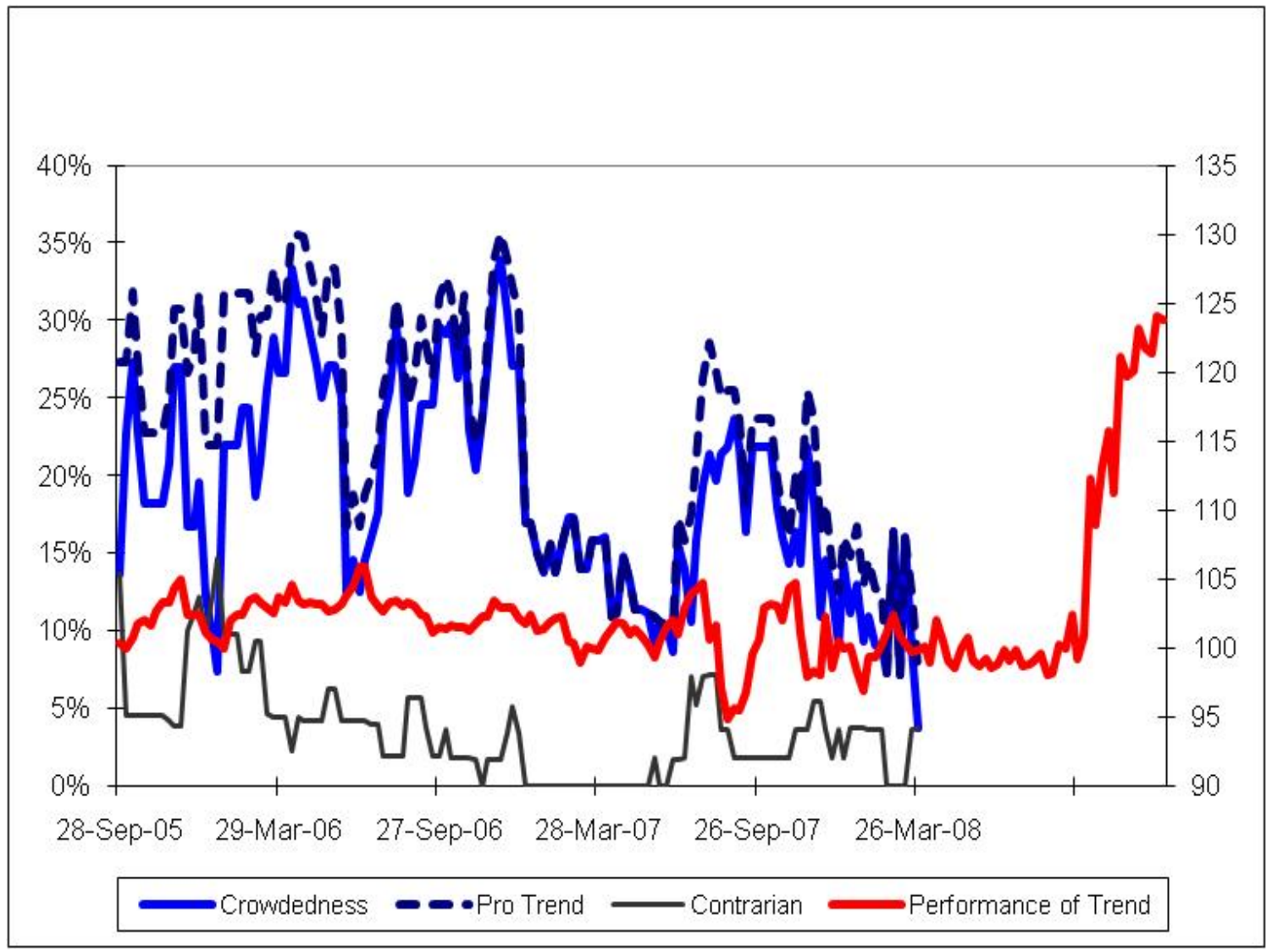

Crowdedness measures are on left-hand scale and Performance measure is on the righthand scale. 


\section{Exhibit 7: Value Crowdedness}

Rolling regression results for $R_{j, t}=\alpha_{j}+\sum_{i} \beta_{i, j} F_{i, t}+\varepsilon_{j, t}$ for manager $j$ active on the platform at least from week $t-25$ onwards. The number of managers varies according to Exhibit 3.

Value crowdedness is defined as in Equation \#2. The first measure for crowdedness is estimated as of 9/28/2005 with 26 weekly observations from 4/06/2005 until 9/28/2005. The last measure of crowdedness is estimated as of $3 / 26 / 2008$ with 26 weekly observations from 10/03/2007 until 3/26/2008. The sample contains 131 rolling windows.

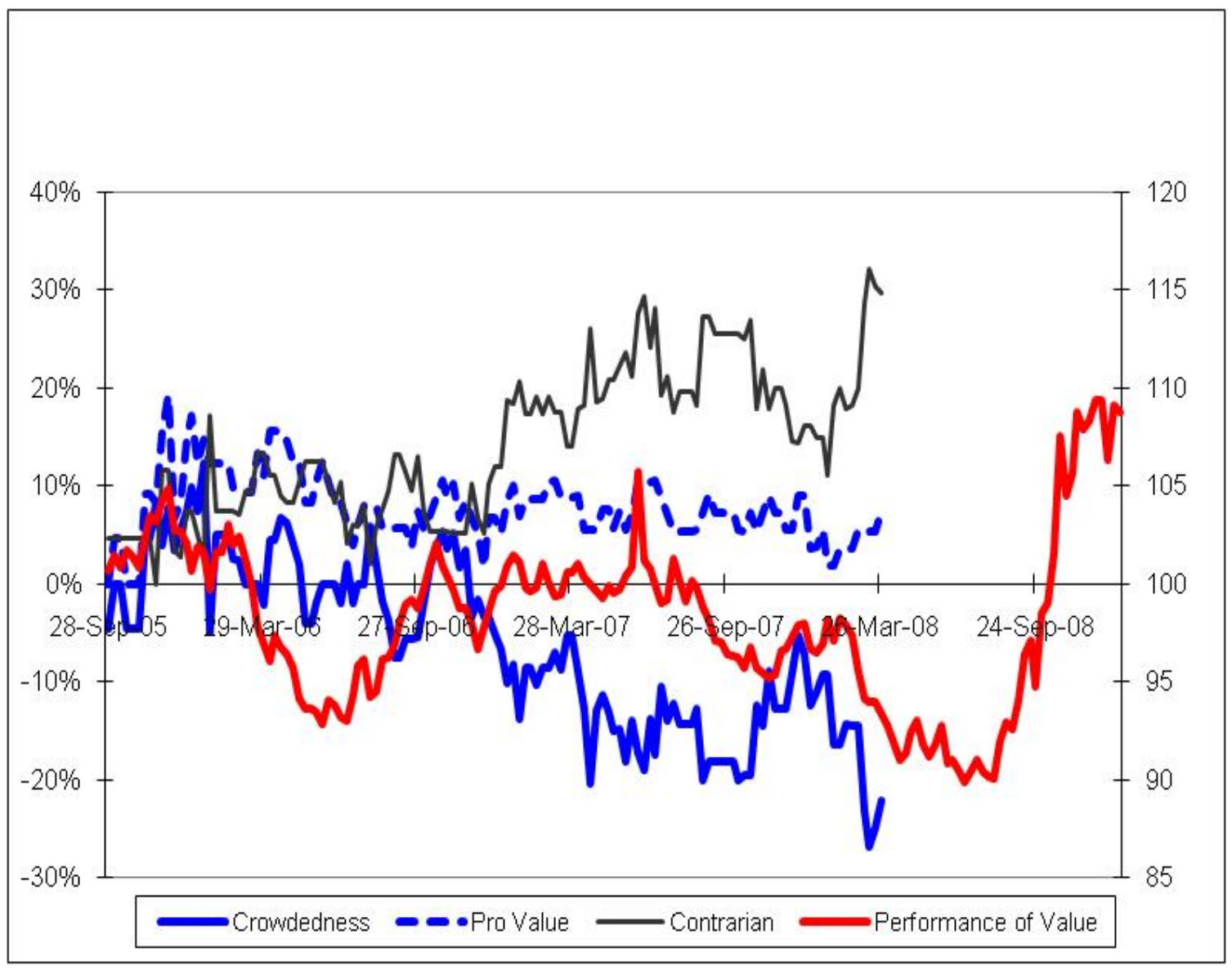

Crowdedness measures are on left-hand scale and Performance measure is on the righthand scale. 
Exhibit 8: Characteristics of Funds at High and Low Points of Crowdedness by Style of Strategy

Panel A: Carry

\begin{tabular}{|c|c|c|c|c|}
\hline & $\begin{array}{c}\text { \# funds on the } \\
\text { platform }\end{array}$ & $\begin{array}{c}\text { \# funds with } \\
\text { significant carry } \\
\text { exposure }\end{array}$ & $\begin{array}{c}\text { \# funds with } \\
\text { significant } \\
\text { negative carry } \\
\text { exposure } \\
\text { (contrarian) }\end{array}$ & $\begin{array}{c}\text { \# funds with } \\
\text { no significant } \\
\text { carry exposure }\end{array}$ \\
\hline Dec 28, 2005 & 41 & 2 & 5 & 34 \\
\hline $\begin{array}{c}\text { Same / dropped- } \\
\text { out / converted }\end{array}$ & $15 / 13 / 13$ & $1 / 0 / 1$ & $2 / 2 / 1$ & $12 / 11 / 11$ \\
\hline March 26, 2008 & 54 & 22 & 5 & 27 \\
\hline $\begin{array}{c}\text { new / old / } \\
\text { converted }\end{array}$ & $26 / 28 / 0$ & $11 / 1 / 10$ & $2 / 2 / 1 /$ & $13 / 12 / 2$ \\
\hline
\end{tabular}

Panel B: Trend

\begin{tabular}{|c|c|c|c|c|}
\hline & $\begin{array}{c}\text { \# funds on the } \\
\text { platform }\end{array}$ & $\begin{array}{c}\text { \# funds with } \\
\text { significant } \\
\text { trend exposure }\end{array}$ & $\begin{array}{c}\text { \# funds with } \\
\text { significant } \\
\text { negative trend } \\
\text { exposure } \\
\text { (contrarian) }\end{array}$ & $\begin{array}{c}\text { \# funds with no } \\
\text { significant } \\
\text { trend exposure }\end{array}$ \\
\hline Dec 6, 2006 & 59 & 21 & 1 & 37 \\
\hline $\begin{array}{c}\text { Same / } \\
\text { dropped-out / } \\
\text { converted }\end{array}$ & $24 / 18 / 17$ & $2 / 5 / 14$ & $0 / 0 / 1$ & $22 / 13 / 2$ \\
\hline March 26, 2008 & 54 & 4 & 2 & 48 \\
\hline $\begin{array}{c}\text { new / old / } \\
\text { converted }\end{array}$ & $13 / 41 / 0$ & $1 / 2 / 1$ & $1 / 0 / 1$ & $11 / 22 / 15$ \\
\hline
\end{tabular}

Panel C: Value

\begin{tabular}{|c|c|c|c|c|}
\hline & $\begin{array}{c}\text { \# funds on the } \\
\text { platform }\end{array}$ & $\begin{array}{c}\text { \# funds with } \\
\text { significant } \\
\text { value exposure }\end{array}$ & $\begin{array}{c}\text { \# funds with } \\
\text { significant } \\
\text { negative value } \\
\text { exposure } \\
\text { contrarian) }\end{array}$ & $\begin{array}{c}\text { \# funds with no } \\
\text { significant } \\
\text { value exposure }\end{array}$ \\
\hline Jan 18, 2006 & 41 & 6 & 1 & 34 \\
\hline $\begin{array}{c}\text { Same / } \\
\text { dropped-out / } \\
\text { converted }\end{array}$ & $15 / 12 / 14$ & $0 / 2 / 4$ & $0 / 1 / 0$ & $15 / 9 / 10$ \\
\hline March 12,2008 & 56 & 3 & 18 & 35 \\
\hline $\begin{array}{c}\text { new / old / } \\
\text { converted }\end{array}$ & $27 / 29 / 0$ & $1 / 0 / 2$ & $8 / 0 / 10$ & $18 / 15 / 2$ \\
\hline
\end{tabular}


Exhibit 9: Correlations of Crowdedness Measures with Lagged Performance of Trading Strategies

Panel A: Sept 28, 2005 - March 26, 2008 (131 weekly observations)

\begin{tabular}{|c|c|c|c|}
\hline & $\begin{array}{c}\text { Carry- } \\
\text { Crowdedness }\end{array}$ & $\begin{array}{c}\text { Trend- } \\
\text { Crowdedness }\end{array}$ & $\begin{array}{c}\text { Value- } \\
\text { Crowdedness }\end{array}$ \\
\hline $\begin{array}{c}\text { Cumulative Carry } \\
\text { Performance (26 weeks) } \\
\text { Lagged 26 weeks }\end{array}$ & $40 \%$ & $2 \%$ & \\
\hline $\begin{array}{c}\text { Cumulative Trend } \\
\text { Performance } \\
\text { (26 weeks) } \\
\text { Lagged 26 weeks }\end{array}$ & & & \\
\hline $\begin{array}{c}\text { Cumulative Value } \\
\text { Performance } \\
\text { (26 weeks) } \\
\text { Lagged 26 weeks }\end{array}$ & & $-25 \%$ & \\
\hline
\end{tabular}

Panel B: Jan 3, 2007 - March 26, 2008 (65 weekly observations)

\begin{tabular}{|c|c|c|c|}
\hline $\begin{array}{c}\text { Cumulative Carry } \\
\text { Performance (26 weeks) } \\
\text { Lagged 26 weeks }\end{array}$ & $56 \%$ & $\begin{array}{c}\text { Trend- } \\
\text { Crowdedness }\end{array}$ & $\begin{array}{c}\text { Value- } \\
\text { Crowdedness }\end{array}$ \\
\hline $\begin{array}{c}\text { Cumulative Trend } \\
\text { Performance } \\
\text { (26 weeks) } \\
\text { Lagged 26 weeks }\end{array}$ & & $7 \%$ & \\
\hline $\begin{array}{c}\text { Cumulative Value } \\
\text { Performance } \\
\text { (26 weeks) }\end{array}$ & & & \\
Lagged 26 weeks & & $5 \%$ \\
\hline
\end{tabular}

Panel C: Sept 28, 2005 - December 27, 2006 (66 weekly observations)

\begin{tabular}{|c|c|c|c|}
\hline & $\begin{array}{c}\text { Carry- } \\
\text { Crowdedness }\end{array}$ & $\begin{array}{c}\text { Trend- } \\
\text { Crowdedness }\end{array}$ & $\begin{array}{c}\text { Value- } \\
\text { Crowdedness }\end{array}$ \\
\hline $\begin{array}{c}\text { Cumulative Carry } \\
\text { Performance (26 weeks) } \\
\text { Lagged 26 weeks }\end{array}$ & $-15 \%$ & & \\
\hline $\begin{array}{c}\text { Cumulative Trend } \\
\text { Performance } \\
\text { (26 weeks) } \\
\text { Lagged 26 weeks }\end{array}$ & & $-12 \%$ & \\
\hline $\begin{array}{c}\text { Cumulative Value } \\
\text { Performance } \\
\text { (26 weeks) }\end{array}$ & & & $-36 \%$ \\
Lagged 26 weeks & & & \\
\hline
\end{tabular}

